\title{
CSCL-Based Pre-Service Teacher Program as Knowledge Building
}

\author{
Jun Oshima, \& Ritsuko Oshima \\ Shizuoka University, Japan
}

\begin{abstract}
The study reports two design experiments on the pre-service teacher program to advance their understanding of learning as knowledge building. We designed the course with a CSCL tool. In the first year, we did not have information on students' characteristics. Analyses of students' final essays and their discourse activities on the CSCL showed: (1) that we failed to improve students' understanding at our expected level, (2) that collaborative students reached a deeper understanding than isolated students, and (3) that students' beliefs of didactic instruction resisted the new perspective on learning we introduced. In the second year, we designed the course to overcome students' resistance and to facilitate more frequent collaboration among them by: (1) making the course project-based, (2) having students in a small group use a computer for their collaboration between groups, and (3) involving them in collaborative problem-solving as learners. Results in the second year, compared with those in the first year, showed a crucial improvement of students' conceptual understanding.
\end{abstract}

Keywords: CSCL, pre-service teacher program, knowledge building.

\section{DESIGN EXPERIMENTS IN TEACHER PROFESSIONAL DEVELOPMENT}

The purpose of the course we designed was to have pre-service teachers acquire conceptual understanding of learning as knowledge building and how to design the classroom environment to facilitate learners' knowledge building using a CSCL technology. Since the course was scheduled as an intensive summer workshop in four to five days, we had to consider a different approach from designing similar courses in a semester (e.g., Oshima, \& Oshima, 2002). Students (49 in the first year, and 51 in the second year) in the Faculty of Humanities and Social Sciences took the course as part of their requirement for teacher certificates. 
In designing the course, we referred to the framework of the community of learners by Brown and Campione (1996). The curriculum was mostly students' discourse-centered. Learning contents were designed to facilitate problem-based and project-based learning with authentic tasks. For students to share their ideas, we implemented a CSCL system, Knowledge Forum ${ }^{\circledR}$. In the first year, we took a general approach to designing the course with no information on students' characteristics. In the second year, based on our evaluation on the first year's design, we could design the course more specifically for the target students.

\section{DESIGN EXPERIMENT-1}

\subsection{Course Design}

The course was designed from the perspectives of: (1) learning contents, (2) learning activities, (3) discourse structure, and (4) the CSCL support.

First, the main goal of the course was to improve students' ability to use the theory of "distributed human intelligence" in considering lesson plans in their major subjects. To this end, we designed the contents of "distributed intelligence," and "situated learning" with examples. We also prepared contents of educational practices based on the conception of "cognitive apprenticeship (Collins, Brown, \& Newman, 1989)" so that they could link their conceptual understanding to practice.

Second, students' activities were designed as repeated sequences of a lecture-based study, problem-based learning at individual, small group, or class-as-a-whole level, and reflection at a benchmark session. The course was conducted in four days. During the first two and a half days when students studied conceptual understanding of distributed intelligence and learning, each individual student used Knowledge Forum ${ }^{\mathbb{B}}$ to collaboratively construct their shared ideas on distributed intelligence and learning as participation in authentic practices. Then, during the remaining day and a half, they conducted project-based learning to study and evaluate Japanese practices.

Third, we designed a course where students engaged in three different phases of discourse: individual-based, group-based, and class-as-a-whole exchange of ideas. In the first stage, we designed students' discourse activities as individual-based exchange of ideas followed by class-as-awhole discourse. In the second stage, we designed their discourse activities as group-based exchange of ideas followed by the benchmark session.

Fourth, we used Knowledge Forum ${ }^{\circledR}$ to facilitate students' discourse as individual-based and group-based exchange of ideas. We expected that the asynchronous discourse tool could guarantee individual contributions to the online discussion. 


\subsection{Evaluation}

The course design was evaluated from two perspectives. First, we evaluated scores of final essays. The essay required students to design lesson plans in their major subjects. Students were allowed to write essays either individually or in collaboration. Two experts independently evaluated each essay from the four perspectives with 5 point-scales: (1) whether knowledge sharing through collaborative learning is appropriately designed, (2) whether a CSCL technology is implemented in appropriate contexts of learning, (3) whether designed activities are practically feasible in the scheduled timeline, and (4) whether goal structures are articulate enough for students to engage in their project-based learning.

Another set of measures was students' discourse activities on Knowledge Forum ${ }^{\circledR}$. We evaluated how and what knowledge building discourse students engaged in. The analyses were conducted quantitatively and qualitatively by referring to the concept of "collective cognitive responsibility" (Scardamalia, 2002). The structure of students' discourse was analyzed with respect to "knowledge access," and "knowledge exchange." Knowledge access would happen when students read others' notes. Knowledge exchange would happen when students put their ideas on others' notes, i.e., producing note threads. Further, qualities of students' discourse were evaluated based on "four commitments to progressive discourse as science" (Bereiter, 1994). Knowledge building discourse should be scientific and progressive, and satisfy: (1) commitment to work toward common understanding satisfactory to all, (2) commitment to frame questions and propositions in ways that enable evidence to be brought to bear on them, (3) commitment to expand the body of collectively valid propositions, and (4) commitment to allow any belief to be subjected to criticism if it will advance the discourse. Two experts independently evaluated discourse in nonthreaded notes or threads.

Students' final essay. Nineteen of forty-nine wrote their essays individually and 30 worked collaboratively. Because the correlation on scores between the experts was statistically significant, the sum of the four average scores was used as the essay score. The mean score of students' essays was $5.83(\mathrm{SD}=2.89)$. A $t$-test on the mean scores of individual and collaborative essays showed that the mean score of collaborative essays, $6.68(\mathrm{SD}=0.99)$, was significantly higher than that of individual essays, $4.47(\mathrm{SD}=4.18), t(47)=2.79, p<.01$.

Results were unlike what we had been expected. We did not expect that many students (around $40 \%$ in this case) would submit their essays individually. Furthermore, the mean score of their essays was lower than our expectation. They only scored 5.83 of 16 . One remarkable result in the analyses, however, was that the score of collaborative essays was higher than that of individual essays.

Students' discourse activities on Knowledge Forum ${ }^{\circledR}$. Knowledge exchange was analyzed by comparing numbers of users engaged in 
producing each note thread. In the individual phase, threads were produced by 3.16 students on the average $(\mathrm{SD}=2.00$ ), whereas by only 1.14 groups $(\mathrm{SD}=0.36)$ in the project phase. The mean note score on Knowledge Forum $^{\circledR}$ was $6.90(\mathrm{SD}=4.50)$ of 20. A $t$-test showed that the note score in the project phase, $9.54(\mathrm{SD}=5.64)$, was significantly higher than that in the individual phase, $6.14(\mathrm{SD}=3.81), t(231)=5.04, p<.01$. Thus, results suggest that: (1) students were not frequently engaged in knowledge exchange between groups in the project phase, (2) the quality of students' discourse was not satisfactory, and (3) students were, however, involved in more highly scored discourse in the project phase compared with the individual phase.

\subsection{Discussion}

Although collaborative activities like project-based learning and collaborative writing of essays were found to have positive effects on students' conceptual understanding, results showed that our design in the first year was not appropriate for facilitating such collaborative activities. We considered the following reasons for our unsuccessful course design. First, from our observation and interviews with some students after the course, we found that many students had strong resistance to the use of computers in education. Their resistance was amplified through their use of Knowledge Forum ${ }^{\circledR}$ as a main tool for communication at the individual and group-based exchange of ideas. We intended to design the use of Knowledge Forum ${ }^{\circledR}$ as a reflection tool guaranteeing each student's contribution to the online discourse. Students did not see the tool in that way. In their online discourse, they raised criticisms to educational computing with reasons such as "The use of computers makes kids' vision worse", "I think that computercommunication is not humane", and so on. The second author (the course instructor) and the first author attempted to adjust their discourse in a more productive way by proposing ideas on the effectiveness of computers in education. We failed to have them recognize the productive aspect of educational computing based on the theory of distributed intelligence.

Second, strong dependence on the asynchronous communication tool, particularly at the individual-based exchange of ideas, made learners who were unfamiliar with the style of communication hesitate to collaborate with others. Unfamiliar students frequently expressed their ideas as single notes, but most of the notes were followed up by others.

Finally, although we found collaborative activities led students to higher levels of understanding than did individual activities, their collaboration was localized within their groups but did not frequently happen beyond the group boundaries, i.e., the discourse was asymmetric between groups. One possibility might be that students had to devote their efforts to their group work. They were divided into project groups in the late stage of the course, and had to manage their groupwork. This might keep them from going beyond their group boundaries. Another possibility might 
be that the project-based learning was not designed in a way for students to collaborate with other groups. In the project-based learning phase, students discussed educational practices they found on the WWW. They were interested in practices in their major subjects but not others. The group structure of students with the same major subjects might not support collaboration between groups majoring in different subjects.

\section{DESIGN EXPERIMENT 2}

\subsection{Course Design}

Learning contents were prepared for having students engage in discourse on the same conceptual artifacts. What students were expected to do in the first year was to manage their own experiences in schooling, the new concepts of distributed intelligence and learning, and some examples of good practices as resources. We found that resources provided by the instructor were not sufficiently understood and appropriately utilized by students. In the second year, we attempted to design project-based learning where students themselves engage in collaborative problem solving on a task so that they could share the same experiences as learners. For this purpose, we used a task called "rescue at the Boone's meadow" from the Jasper project (CTGV, 1997). We showed students the video then asked them to think of their solutions in their groups. We used their solutions as conceptual artifacts for their discourse on Knowledge Forum ${ }^{\circledR}$ to construct their class solution. We further asked students to collaboratively report their reflections on their problem solving processes for their further knowledge building discourse on collaborative learning as a way to facilitate distributed intelligence among learners. The goal of their final essays was also changed from designing lesson plans in their major subjects to designing plans in time for integrated studies where learners have to integrate their knowledge resources from various subject matters.

Students engaged in project-based learning in all stages of the course. Students participated in project-based learning in homogeneous groups, i.e., groups of students who were majoring the same subjects, in the first stage, then worked in heterogeneous groups, i.e., groups of students who were majoring in different subjects. Projects in the first stage were designed in such a way that they collaboratively worked on problem solving for understanding new concepts of distributed intelligence and learning based on their experiences of solving the Jasper problem as learners. Projects in the second stage, on the other hand, were designed for them to consider educational practice research from KIE and WISE research group (Linn, and Hsi, 2000) and our research group on Knowledge Forum ${ }^{(\mathbb{R})}$ (Oshima, Oshima, Murayama, Inagaki, Takenaka, Nagato, Yamamoto, Nakayama, \& Yamaguchi, 2002). Regrouping in the second stage was 
legitimate for students because they needed to work with others who had different subject matter knowledge to consider lesson plans for the integrated studies. It was also legitimate for us as designers to make their group works more constructive. We had five teaching assistants who observed and videotaped students' activities in each group (one for two or three groups). The assistants informed us who had strong leadership, collaborative characteristics, and so on. With the provided information, we could arrange heterogeneous groups to make their social dynamics more constructive and collaborative.

Face-to-face discussion within groups as objects for discourse on Knowledge Forum ${ }^{\text {(2) }}$. In the second year, we encouraged students' discussion within groups face-to-face. We prepared computers in the room so that each group of students could use one computer collaboratively. Desks were mobile for them to create small islands for collaborative works. We also prepared another computer room near the main room just in case they wanted to use computers individually. They were instructed to report their groups' ideas, then read other groups' ideas to comment on. Their discourse on line was further used by the instructor to reflect on what they did on the day as a community and discuss with them what to do on the next day. The instructor and teaching assistants regularly elicited students' reflection on what they were doing by asking provoking questions such as "How did you understand the task the instructor told?", "Is your groupwork going well?", "If not, what do you think are problems you have to overcome?", and so on.

\subsection{Evaluation}

The main purpose of the analyses here is to confirm that the course design in the second year led students to better qualities of knowledge building discourse and conceptual understanding.

Comparison of students' characteristics. At the beginning of the course in both years, we conducted a multiple-choice questionnaire to ask students about subjects they were majoring in, computer literacy level (e.g., years of experiences and how often they use computers), and their typing skills. We found no significant differences by Chi-square tests.

Comparison of scores on final essays. Multiple $t$-tests showed that the second year score was significantly higher than the first year grand mean score, $t(98)=8.11, p<.01$, and the score of collaborative essays, $t(79)=$ $7.40, p<.01$ (Table 1).

Comparisons of students' discourse activities. We compared knowledge access and exchange in the first year's project phase and the second year (Table 2). Multiple t-tests showed that significantly more groups in the second year accessed thread notes, $t(66)=10.16, p<.01$, and contributed to knowledge exchange, $t(66)=9.55, p<.01$.

Table 3 shows mean scores of discourse. Multiple $t$-tests showed that the discourse score in the second year was significantly higher than the first 
year grand mean, $t(293)=12.50, p<.01$, and mean in the project phase, $t(112)=5.95, p<.01$.

Table 1. Mean Scores of Students' Final Essays (SDs).

\begin{tabular}{lll}
\hline 1st Year Grand Mean & $\begin{array}{l}\text { 1st Year Mean of } \\
\text { Collaborative Essays }\end{array}$ & 2nd Year Mean \\
\hline $5.83(2.89)$ & $6.68(0.99)$ & $10.18(2.47)$ \\
\hline
\end{tabular}

Table 2. Mean Numbers (SDs) of Groups Contributing to Knowledge Exchange and Accessing.

\begin{tabular}{|c|c|c|}
\hline & Number of contributing groups & Number of accessing groups \\
\hline 1 st year & $1.14(0.36)$ & $5.54(1.60)$ \\
\hline 2nd year & $5.18(2.32)$ & $9.48(1.80)$ \\
\hline \multicolumn{3}{|c|}{ Table 3. Mean scores of discourse in notes (SDs). } \\
\hline 1 st year grand mean & $\begin{array}{l}\text { Ist year mean } \\
\text { in the project phase }\end{array}$ & 2nd year mean \\
\hline $6.90(4.50)$ & $9.54(5.64)$ & $14.44(2.92)$ \\
\hline
\end{tabular}

\subsection{Discussion}

First, the comparison of final essay scores suggests that we succeeded in designing the course better in the second year. The improvement could not be interpreted only by our instruction to students to collaboratively submit their final essay. The task was changed from planning lessons in their major subjects to integrated studies. The groups were heterogeneous in the second year. Learning activities were also revised so that they were more engaged in project-based learning. All the changes in the course design would affect better outcomes.

Second, it was found that students' discourse activities were meaningfully improved in comparison with those in the first year. The quantitative and qualitative comparisons suggest that students' discourse activities were more symmetric, i.e., they were involved in knowledge access and exchange between groups. Further, the quality of their discourse in notes was significantly higher. We consider that this would happen because students could work on their discourse as groups. The face-to-face discourse within groups scaffolded by the provoking questions could generate conceptual artifacts sharable with other groups.

Another important reason may be that they produced their sharable experiences as learners during the course work. In the first year, students had to manage how to coordinate their philosophical views on education and new concepts of distributed intelligence and learning. It was found to be very difficult to share ideas and collaboratively improve their knowledge with new concepts as conceptual artifacts when their belief systems did not accept the concepts. In the second year, they worked on the new concepts by engaging in discourse on their shared experiences constructed during the course. The discourse in the second year was more sharable among students, open to criticisms, and improvable through synthesis of different points of 
views. Thus, we could make students execute a different and more constructive type of "epistemic agency" (Scardamalia, 2002).

\section{REFERENCES}

Bereiter, C. (1994). Implication of postmodernism for science education: A critique. Educational Psychologist, 29(1), 3-12.

Bereiter, C. (2002). Education and mind in the knowledge age. Mahwah, NJ: Lawrence Erlbaum.

Brown, A. L., \& Campione, J. C. (1996). Psychological theory and the design of innovative learning environments: On procedures, principles, and systems. In L. Shauble \& R. Glaser (Eds.), Innovations in Learning: New Environments for Education (pp. 289-325). Mahwah, NJ: Lawrence Erlbaum.

Collins, A., Brown, J. S., \& Newman, S. E. (1989). Cognitive apprenticeship: Teaching the crafts of reading, writing, and mathematics. In L. B. Resnick (Ed.), Knowing, learning, and instruction: Essays in honor of Robert Glaser (pp. 453-494).Mahwah, NJ: Lawrence Erlbaum.

CTGV (1997). The Jasper Project. Mahwah, NJ: Lawrence Erlbaum.

Linn, M., \& Hsi, S. (2000). Computers, teachers, peers: Science learning partners. Mahwah, NJ: Lawrence Erlbaum.

Oshima, J., Oshima, R., Murayama, I., Inagaki, S. Takenaka, M., Nagato, M., Yamamoto, T., Nakayama, H., Yamaguchi, E. (2002). CSCL Design Experiments in Japanese Elementary Science Education: Hypothesis Testing Lesson and Collaborative Construction Lesson. Paper presented at the Annual Meeting of the AERA, New Orleans.

Oshima, J., \& Oshima, R. (2002). Coordination of Asynchronous and Synchronous Communication. In Koschmann, T., Hall, R., Miyake, N. (Eds.), CSCL2. Mahwah, NJ: Lawrence Erlbaum.

Scardamalia, M. (2002). Collective cognitive responsibility for the advancement of knowledge. In B. Jones (Ed.), Leberal Education in the Knowledge Age. Chicago, IL: Open Court. 